\title{
Article
}

\author{
Doi 10.5943/sif/5/1/29
}

\section{Xylaria oxyacanthae (Xylariaceae), a new record on Diospyros melanoxylon from India}

\section{Himani S and Krishnappa $\mathbf{M}^{*}$}

Department of studies and Research in Applied Botany, School of Biological sciences, Kuvempu University, Shankaraghatta - 577451, Karnataka, India

Himani S, Krishnappa M 2020 - Xylaria oxyacanthae (Xylariaceae), a new record on Diospyros melanoxylon from India. Studies in Fungi 5(1), 485-490, Doi 10.5943/sif/5/1/29

\begin{abstract}
Xylaria is the largest genus in Xylariaceae with wide range of hosts, and highly diversified species. In this study, Xylaria samples were collected from buried fruits of Diospyros melanoxylon in India. Morphological characteristics and molecular phylogenetic analysis of internal transcribed spacer (ITS) data recovered supports our stain is Xylaria oxyacanthae, a new record to India. A detailed morphological description and comparison of closely related taxa are provided in this study.
\end{abstract}

Key words - Fungal taxonomy - ITS - Karnataka - Molecular phylogeny

\section{Introduction}

Xylariaceae Tul. \& C. Tul. belongs to the order Xylariales Nannf. and is the largest ascomycete found in most of the countries (Whalley 1996). Xylariaceae containing 32 genera and 1,236 species (Hyde et al. 2020). Members of this family have various hosts range and are considered as endophytic, parasitic, saprophytic, and symbiotic on insect nests (Daranagama et al. 2016). Xylaria Hill ex Schrank. species are characterized by erect stroma, varying in shape from cylindrical to clavate, or irregularly shaped with fertile parts, cylindrical asci with eight ascospores and a J+, apical ring in Melzer's reagent (Sir et al. 2012, Daranagama et al. 2016, Sanjit et al. 2018).

Xylaria oxyacanthae Tul. \& C .Tul has been reported on many different hosts worldwide as a species associated with fruits/seeds of Carpinus (Betulaceae), Carya (Juglandaceae), Cornus (Cornaceae), Crataegus and Prunus (Rosaceae) (Tulasne \& Tulasne 1863, Stowell \& Rogers 1983, Kujawa \& Karasiński 2007, Rogers et al. 2008, Ju et al. 2018). In this paper aimed to present a new record of $X$. oxyacanthae on fruits of Diospyrous melanoxylon Roxb. D.Melanoxylon is a deciduous tree found along the Western Ghats of India and is a native plant of India and Sri Lanka (Orwa et al. 2009).

A new record of $X$. oxyacanthae on fruits of Diospyrous melanoxylon was introduced based on morphological characteristics and phylogenetic analysis of ITS.

\section{Materials \& methods}

\section{Sample collection and morphological study}

Buried and decomposing fruits of Diospyros melanoxylon were collected near Bhadra Wildlife Sanctuary, Chikkamagaluru District, Karnataka, India during May-July 2019. 
Morphological characters of stromata, colour, shape, size, and habitat were recorded in the field. The photograph was done using a digital camera (Sony cyber-shot). Stromata were carefully removed from the ground using knife and cleaned with soft brush. Specimen was collected in paper bag and dried in low temperature $15-25^{\circ} \mathrm{C}$. Surface and longitudinal section of the stromata were studied by using stereo microscope (MagnUs), micro-morphological characters such as color, shape and size of perithecia and ascospores were noticed using compound microscope (Olympus CH20i). Melzer's reagent was conducted to detect the presence or absence of apical ring. The voucher specimen was deposited in Department of Botany, Kuvempu University, Shankaraghatta, Shivamogga, Karnataka, India. Facesoffungi number was registered as per Jayasiri et al. (2015).

\section{DNA extraction, PCR amplification, and sequencing}

Genomic DNA was extracted from $250 \mathrm{mg}$ of fresh ascomata using CTAB method. Internal transcribed spacer (ITS) region was amplified by using ITS4 and ITS5 primers (White et al. 1990). Polymerase chain reaction (PCR) was done using thermocycle (Eppendorf, Germany) programmed of initial denaturation for $2 \mathrm{~min}$ at $94^{\circ} \mathrm{C}$, denaturation for $50 \mathrm{sec}$ at $94^{\circ} \mathrm{C}$, annealing followed by 30 cycles of $30 \mathrm{sec}$ at $48^{\circ} \mathrm{C}$, extension of $1 \mathrm{~min} 30$ seconds at $72^{\circ} \mathrm{C}$ and a final extension of $6 \mathrm{~min}$ at $72^{\circ} \mathrm{C}$. The quality of PCR amplified products was observed on $2 \%$ agarose electrophoresis. A nucleotide BLAST search against GenBank database was done to identify the most closely related sequences. The DNA sequence has been deposited in GenBank (www.ncbi.nlm.nih.gov) with the accession number MN386233.

\section{Alignments and phylogenetic analysis}

The dataset consisted of 15 taxa were used for phylogenetic analysis and Daldinia concentrica (strain Gir_16) was chosen as out-group. The pair wise alignments were carried out manually by using Clustal-W. The evolutionary history was inferred by using the Maximum Likelihood method and Kimura 2-parameter model (Kimura 1980). The tree with the highest log likelihood (-1667.89) is shown. The percentage of trees in which the associated taxa clustered together is shown next to the branches. Initial tree(s) for the heuristic search were obtained automatically by applying Neighbor-Join and BioNJ algorithms to a matrix of pairwise distances estimated using the Maximum Composite Likelihood (MCL) approach, and then selecting the topology with superior log likelihood value. A discrete Gamma distribution was used to model evolutionary rate differences among sites (3 categories $(+G$, parameter $=0.2035)$ ). The tree is drawn to scale, with branch lengths measured in the number of substitutions per site. This analysis involved 15 nucleotide sequences. Codon positions included were 1 st+2nd+3rd+Noncoding.All positions with less than $80 \%$ site coverage were eliminated, (partial deletion option). Evolutionary analyses were conducted in MEGA X (Kumar et al. 2018).

\section{Results}

\section{Phylogenetic analysis}

The ITS dataset comprised 15 sequences, of which Daldinia concentrica (strain Gir_16) was chosen as out-group. There were a total of 485 positions in the final dataset. Maximum likelihood analysis yielded on tree (Fig. 1).

\section{Taxonomy}

Xylaria oxyacanthae Tul. \& C. Tul., Select. Fung. Carpol (Paris) II, p. 15. (1863)

MycoBank number: MB17107; Facesoffungi number: FoF 09454

Stromata erect, which grow up from mummified fruits of Diospyros melanoxylon, branched/unbranched at the base, 4-8 cm in length, 1-3 mm diam, cylindrical, slightly laterally compressed with short acute sterile apices. Externally black with brown fibrous outer layer, internally white to cream. Texture soft to woody, surface roughened with wrinkles. Perithecia 
globose to subglobose 0.3-0.5 mm diam. Ostioles conical-papillate, black. Anamorphic stromata filiform, cylindrical white layer peeling off gradually with yellowish to pinkish acute tip underlying grey-brown layer. Asci cylindrical uniseriate with eight ascospores 100-130 total length $\times 6-8.5 \mu \mathrm{m}$ broad with stipes, Apical ring cuboid, bluing in Melzer's reagent. Paraphyses abundant. Ascospores brown to dark brown, smooth, ellipsoid, inequilateral with broad or narrow ends, measuring 9.5$13.5 \times 4.5-5.0 \mu \mathrm{m}$, with straight germ slit covers full length of the spore.

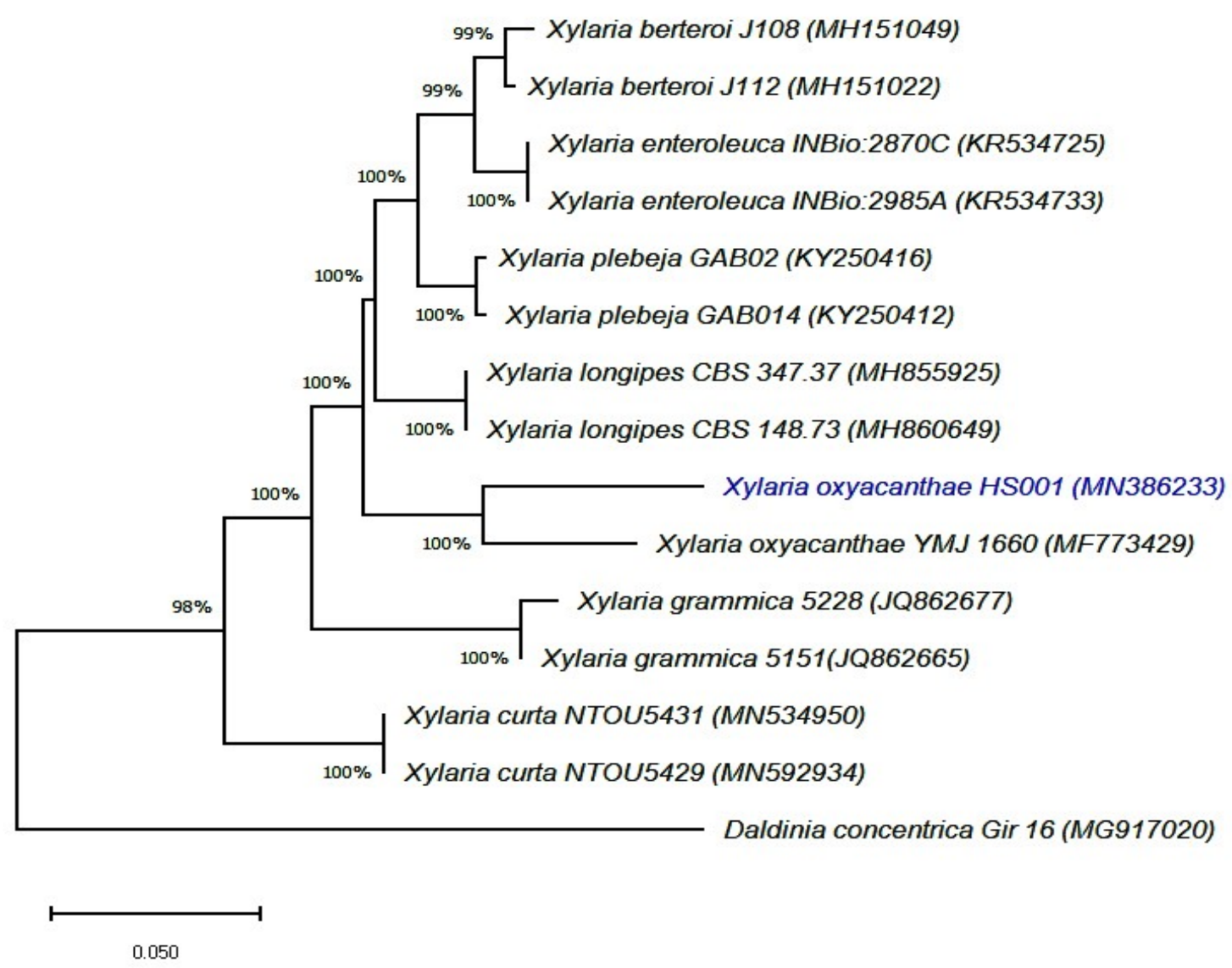

Fig. 1 - Phylogenetic relationship between Xylaria oxyacanthae species, inferred from ITS nucleotide sequence data. The phylogenetic tree obtained by ML analysis with the highest log likelihood (-1667.89) is shown. Values $<80 \%$ are not shown. A new record is highlighted in blue.

Distributions - Crataegus monogyna (Poland), Kujawa \& Karasiński 2007; Crataegus seeds (Europe and North America), Rogers et al. (2008); Plum seeds and Carpinus betulus (France),fruits of Cornus sanguine,seeds of Carpinus sp(Germany),nut remains of Carya sp., seeds of Crataegus monogyna (USA), Ju et al. (2018).

Material examined - INDIA, Karnataka, Shivamogga, Department of Applied Botany, Kuvempu University, on fruits of Diospyrous melanoxylon, 10 Jul 2019, Himani S, collecting code (KUABHS10).

\section{Discussion \& Conclusion}

Thirty-two species of Xylaria are associated with fallen fruits/seed in the world and Xylaria oxyacanthae is one among them (Perera et al. 2020). Most of them are host specific but in case of $X$. oxyacanthae showed various host range on different types of fruits such as Carpinus, Carya, Cornus, Crataegus and Prunus. (Kujawa \& Karasiński 2007, Rogers et al. 2008, Ju et al. 2018). 
The molecular analysis based on ITS, RPB2, and $\alpha$-ACT showed similarities among different host plants (Ju et al. 2018). In our observation the sporocarp developed on the fruits of Diospyrous melanoxylon after one year of the fall of the fruit. Xylaria oxyacanthae possesses sexual and asexual morphs. The common characters observed from the previous studies are X.oxyacanthae found on the buried or mummified fruits in May-July (Autumn-Spring) (Ju et al. 2018). A comparative study of our specimen and data provided by other authors are presented in Table 1. It shows that macroscopic and microscopic characters of our sample are compatible with previous findings. For molecular identification of X.oxyacanthae we have considered only ITS region because there are only few records for other gene sequences (Ju et al. 2018). The phylogenetic analyses confirmed our strain showed $100 \%$ similarity with strain YMJ 1660 . Both morphological and phylogenetic analysis strongly supports that X.oxyacanthae is a new report to India for the host.

Table 1 Comparison of different characteristics of Xylaria oxyacanthae with earlier published works

\begin{tabular}{|c|c|c|c|c|}
\hline Macro-characteristics & San Martin \& Rogers (1989) & Kujawa \& Karasiński (2007) & Fournier (2014) & This study \\
\hline Host & $\begin{array}{l}\text { On seeds of Vitaceae and on } \\
\text { buried leguminous pod }\end{array}$ & On fruits hawthorn & On Crataegus seeds & On Diospyros melanoxylon \\
\hline Stromata & Unbranched or branched & Simple or branched & Simple to furcate & Branched/unbranched \\
\hline Shape & Cylindrical to irregular & Cylindrical & Filiform to narrowly fusiform & Cylindrical \\
\hline Size & 3-7 cm length $\times 1-2.5 \mathrm{~mm}$ diam & $10-60 \mathrm{~mm}$ length $\times 1-4 \mathrm{~mm}$ diam & 34-61 mm length $\times 0.8-2.5 \mathrm{~mm}$ diam & $4-8 \mathrm{~cm}$ in length $\times 1-3 \mathrm{~mm}$ diam \\
\hline External colour & Blackish with gray to brown & Black & Black & Black \\
\hline Internal Colour & White to yellowish & White & White & White to cream. \\
\hline Texture & Soft to woody & & Leathery & Woody \\
\hline Surface & Roughened with wrinkles & & Strongly nodulose & $\begin{array}{l}\text { Surface roughened with } \\
\text { wrinkles }\end{array}$ \\
\hline \multicolumn{5}{|l|}{ Micro-characteristics } \\
\hline Perithecia & Globose or subglobose & Subglobose & Subglobose & Globose to subglobose \\
\hline Ostioles & Finely papillate & & Conic-papillate & Conical-papillate \\
\hline Asci & Asci 8-spored, cylindrical & Asci 8-spored, cylindrical & Asci 8-spored, cylindrical & Asci 8-spored, cylindrical \\
\hline Size & $114-164 \mu \mathrm{m} \times 6-7.5 \mu \mathrm{m}$ & $120-135 \mu \mathrm{m} \times 6-8 \mu \mathrm{m}$ & $130-140 \mu \mathrm{m} \times 8-8.5 \mu \mathrm{m}$ & $100-130 \mu \mathrm{m} \times 6-8.5 \mu \mathrm{m}$ \\
\hline Ascospore Shape & $\begin{array}{l}\text { Ellipsoidal-in equilateral broadly } \\
\text { or narrowly rounded ends }\end{array}$ & In equilateral elliptic to navicular & $\begin{array}{l}\text { Ellipsoid inequilateral with both ends } \\
\text { narrowly rounded to acute or one end } \\
\text { Acute and the other broadly rounded }\end{array}$ & $\begin{array}{l}\text { Ellipsoid, in equilateral with } \\
\text { broad or narrow ends }\end{array}$ \\
\hline Colour & Brown to dark brown & Dark brown to black & Dark brown & Dark brown to brown \\
\hline Size $(\mu \mathrm{m})$ & $(9.5-) 10-11.5(-12) \mu \mathrm{m} \times 5-5.5 \mu \mathrm{m}$ & $10-13(14) \mu \mathrm{m} \times 4.5-6.0 \mu \mathrm{m}$ & $11.4-12.9 \times(4.6) 4.9-5.6(5.9) \mu \mathrm{m}$ & 9.5-13.5 $\mu \mathrm{m} \times 4.5-5.0 \mu \mathrm{m}$ \\
\hline
\end{tabular}




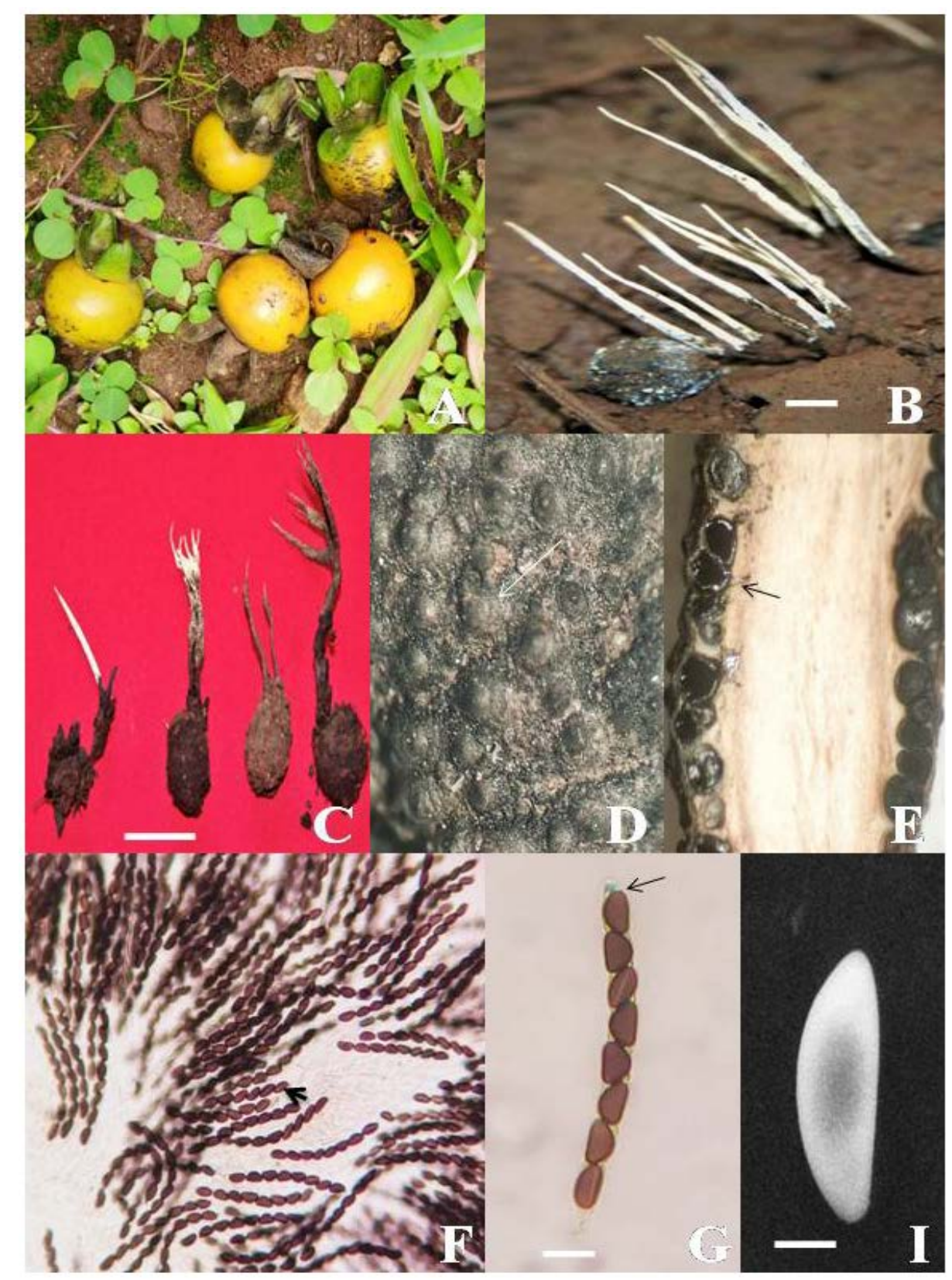

Fig. 2 - Fresh fruits of Diospyros melanoxylon. B Anamorph stage of Xylaria oxyacanthae. C Different growth stage of Stromata on dried fruits. D Arrow mark showing ostioles. E V.S. of stromata with arrow mark showing perithecia. F-G ascospores (arrow mark showing germ slit and apical ring). I SEM image of ascospore. Scale bars: B-C = 4-8 cm, G-I = 9-13 $\mu \mathrm{m}$.

\section{Acknowledgement}

The first author is grateful to Head, Department of studies and Research in Botany, School of Biological sciences, Kuvempu University, for providing all kinds of facilities during the present study.

\section{Reference}

Daranagama DA, Jones EBG, Liu XZ, To-anun C et al. 2016 - Mycosphere Essays 13 - Do xylariaceous macromycetes make up most of the Xylariomycetidae? Mycosphere 7(5), 582601. Doi: $10.5943 /$ mycosphere/7/5/5

Fournier J. 2014 - Update on European species of Xylaria.

(http://www.ascofrance.fr/uploads/xylaria/201406.pdf) 
Hyde KD, Norphanphoun C, Maharachchikumbura SSN, Bhat D et al. 2020 - Refined families of Sordariomycetes. Mycosphere 11(1), 305-1059. Doi: 10.5943/mycosphere/11/1/7

Jayasiri SC, Hyde KD, Ariyawansa HA, Bhat J et al. 2015 - The Faces of Fungi database: fungal names linked with morphology, phylogeny and human impacts. Fungal Diversity 74(1):3-18 Doi: 10.1007/s13225-015-0351-8

Ju YM, Rogers JD, Hsieh HM. 2018 - Xylaria species associated with fallen fruits and seeds,Mycologia, 110: 4, 726-749, Doi: 10.1080/00275514.2018.1469879

Kimura M. 1980 - A simple method for estimating evolutionary rate of base subsFFtitutions through comparative studies of nucleotide sequences. Journal of Molecular Evolution 16: 111-120.

Kujawa A, Karasiński D. 2007 - Xylaria oxyacanthae Tul. et C. Tul., a new species for Poland. Acta Mycologica 42 (1), 75-78.

Kumar S, Stecher G, Li M, Knyaz C, Tamura K. 2018 - MEGA X: Molecular Evolutionary Genetics Analysis across computing platforms. Molecular Biology and Evolution 35, 15471549.

Orwa C, Mutua A, Kindt R, Jamnadass R, Anthony S. 2009 - Agro forestree Database: a tree reference and selection guide version 4.0 (http://www.worldagroforestry.org/sites/treedbs/treedatabases.asp).

Perera RH, Hyde KD, Maharachchikumbura SSN, Jones EBG et al. 2020 - Fungi on wild seeds and fruits. Mycosphere 11(1), 2108-2480. Doi: 10.5943/mycospere/11/1/14.

Rogers JD, Yeomans R, Adams MJ. 2008 - The relationship of Xylaria oxyacanthae to seeds of Crataegus monogyna. North American Fungi 3, 8: 1-5.

San Martin FG, Rogers JD. 1989 - A preliminary account of Xylaria of Mexico. Mycotaxon Vol. XXXIV. No. 2. pp. 283-373.

Sanjit D, Koushik M, Panna D. 2018 - New Distribution Record of Five Species of Xylaria from Tripura, Northeast India. Research \& Reviews: A Journal of Life Sciences 8(1), 1-10p.

Sir EB, Hladki AI, Parrado MF, Romero AI. 2012 - Biodiversity of Xylariaceae (Ascomycota) and their hosts in protected areas from Tucumán (Argentina). Kurtziana 37(2), 35-48.

Stowell EA, Rogers JD. 1983 - Studies on Xylaria oxyacanthae. Mycotaxon 17: 433-444.

Tulasne LR, Tulasne C. 1863 - Selecta Fungorum Carpologia. Vol. II. Paris.

Whalley AJS. 1996 - The xylariaceous way of life. Mycological Research 100: 897-922.

White TJ, Burns T, Lee S, Taylor J. 1990 - Amplification and direct sequencing of fungal ribosomal RNA genes for phylogenetics. In: Innes MA, Gelfand DH, Sninsky JJ, White TJ, eds. PCR protocols, a guide to methods and applications. San Diego: Academic Press. 315322. 